\title{
Stepping behavior and muscle activity of dairy cows on uncomfortable standing surfaces presented under 1 or 4 legs
}

\author{
E. Rajapaksha and C. B. Tucker ${ }^{1}$ \\ Department of Animal Science, University of California, 1 Shields Avenue, Davis 95616
}

\begin{abstract}
The comfort of dairy cattle while standing has important implications for housing design. Research has examined how cattle respond to standing surfaces by presenting options under all 4 legs or under a single leg, but no work, to date, has compared presentation methods. This study examined behavior and muscle activity when cows stood on rough floors under all 4 legs or just 1 hind leg. Three treatments were tested: smooth concrete under all 4 legs (0-ROUGH), a rough surface under all 4 legs $[2 \mathrm{~cm} \times 2 \mathrm{~cm} \times 4 \mathrm{~cm}$ trapezoidal protrusions (4-ROUGH)], and a rough surface only under 1 hind leg, with other legs on smooth concrete (1-ROUGH). Twenty-four healthy Holstein cows stood on each surface for $1 \mathrm{~h} / \mathrm{d}$ in a repeated-measures design. Surface electromyograms (SEMG) were used to evaluate muscle fatigue and total activity. Muscle fatigue was measured using SEMG to evaluate (1) static contractions when cows were continuously weight bearing on each hind leg, before and after $1 \mathrm{~h}$ of standing, and (2) dynamic contractions associated with steps during $1 \mathrm{~h}$ of standing. Behavioral measures included steps per minute, time between each consecutive step, and the latency to lie down after testing. The number of legs affected by roughness influenced both behavioral and physiological responses to flooring. Cows on 1-ROUGH stepped twice as often with the rough-treated leg and one-half as much with the hind leg on smooth concrete compared with other surfaces. Similarly, on the 1-ROUGH surface, total muscle activity was reduced in the leg on the rough surface, and muscle activity was more sustained $(3 \times$ higher $)$ in the other hind leg, suggesting that cows avoid possible discomfort under 1 leg by using muscles in the other. In the 4-ROUGH treatment, time between steps was more variable than on the other 2 treatments (coefficient of variation, 4-ROUGH: 245; 1-ROUGH: 208; 0-ROUGH: $190 \pm 5.8 \%$ ), likely because cows could not move away from this uneven flooring. Thus, the method of presentation of stimuli used to
\end{abstract}

Received July 22, 2014.

Accepted October 1, 2014.

${ }^{1}$ Corresponding author: cbtucker@ucdavis.edu evaluate comfort while standing altered the response. Stepping rate and SEMG changed when roughness was under a single leg, whereas timing between consecutive steps was more variable with rough flooring under all 4 legs. These results have implications for the design of experiments evaluating standing comfort in the future. Key words: behavior, electromyogram, muscle fatigue, flooring

\section{INTRODUCTION}

Flooring surface is an important feature of housing design. Concrete is used in $56 \%$ of US dairy operations (USDA, 2009). However, concrete flooring has been identified as a risk factor for development of hoof and leg lesions (Vokey et al., 2001; Somers et al., 2003) and lameness in cattle (Cook, 2003; Vanegas et al., 2006). When concrete floors were compared with a more compressible surface, such as rubber, cows spent more time standing on (Platz et al., 2008; Haufe et al., 2009; Ouweltjes et al., 2009) and showed preferences for (Tucker et al., 2006; Telezhenko et al., 2007) rubber, indicating that concrete may be uncomfortable. Although cows stand on concrete for 11 to $15 \mathrm{~h} / \mathrm{d}$ in most freestall barns (Ito et al., 2009), only a few studies have attempted to investigate responses while exclusively standing (Cooper et al., 2007; Krebs et al., 2011; Chapinal and Tucker, 2012).

The research on responses to standing can be divided into 2 methods of presentation: evaluation of flooring features where all 4 legs are on standard surfaces (e.g., concrete or rubber), and where only 1 leg experienced something different, such as pain or exposure to alternative flooring. Experiments that present treatments under all 4 legs have used stepping rate to examine the effect of standing time (Cooper et al., 2007), floor slope (Rajapaksha and Tucker, 2014), or surface compressibility (Krebs et al., 2011; Chapinal and Tucker, 2012). In all of these experiments, steps increased over time, but no differences were observed between flooring treatments. Thus, to date, it is unclear whether increased stepping rates reflect discomfort associated with standing surfaces. In experiments that present alternative flooring or pain under a single hoof, weight shifting 
from 1 leg to the other and number of steps increased with lameness (Pastell and Kujala, 2007; Rushen et al., 2007; Chapinal et al., 2010) or when a single hind leg of a healthy cow was placed on protruding rocks or screws (Neveux et al., 2006). When animals were given pain relief (Rushen et al., 2007; Chapinal et al., 2010), weight shifting and stepping were reduced. Thus, when pain or alternative surfaces are presented under a single hoof, stepping behavior distinguishes among treatments and provides insight into animal welfare. To date, work that compares the 2 methods of presentation (under a single vs. all 4 legs) with an adequate sample size is limited.

In addition to the stepping and weight shifting measured in previous work, other tools could provide additional insight into comfort while standing. Evaluation of skeletal muscle activity and muscle fatigue play a key role in understanding human responses to standing and correspond to verbal reports of discomfort (Kim et al., 1994). Skeletal muscle activity can be measured in healthy cattle (Ternman et al., 2012; Rajapaksha and Tucker, 2014). In addition, weight-bearing correlates with muscle activity in animals (De Leon et al., 1998; Gregor et al., 2006); thus, muscle activity and fatigue captured by surface electromyograms (SEMG) may provide insight into the effects of rough standing surfaces that is similar to data collected with load cells. For example, cows standing with 1 hind leg on a surface with rocks or screws reduce weight-bearing on that leg and transfer the weight to the contralateral leg (Neveux et al., 2006). In addition, it is known that neither weight distribution among legs (Chapinal et al., 2010) nor muscle activity (Rajapaksha and Tucker, 2014) is correlated with visually observable stepping behavior. Thus, evaluating both stepping behavior concurrently with SEMG may provide additional information about responses to standing.

The objective of this study was to compare 2 methods of presentation of rough standing surfaces ( 1 or all 4 legs on rough concrete surface) in terms of stepping behavior and skeletal muscle activity. We hypothesized that cows would show increased stepping rate, total muscle activity, and indicators of muscle fatigue on rough flooring, and that the most marked response would occur when all 4 legs were on this surface. We also hypothesized that presenting the rough flooring under a single hind leg would reduce muscle activity and increase steps taken for that leg.

\section{MATERIALS AND METHODS}

\section{General Information}

This experiment was conducted at the University of California, Davis, dairy facility between September and
November of 2011. All procedures were approved by the Institutional Animal Care and Use Committee.

\section{Animals and Housing}

Twenty-four lactating Holstein-Friesian dairy cows were tested in groups of 6 . All were clinically sound, with a gait score $\leq 2$ (Flower and Weary, 2006). Cows had an average BW of $661 \pm 53 \mathrm{~kg}$, BCS of $2.8 \pm$ 0.3 ; DIM of $161 \pm 64$, and daily milk production of $35.5 \pm 5.5 \mathrm{~kg}$ (mean $\pm \mathrm{SD})$. Cows were housed in a pen with 24 head-to-head freestalls $(1.2 \mathrm{~m} \times 2.4 \mathrm{~m}$; $1 \mathrm{cow} /$ freestall) that were deep-bedded with sand and had a neck rail located $106 \pm 2 \mathrm{~cm}$ above the stall surface. The cows were milked at 0600 and $1700 \mathrm{~h}$, had ad libitum access to water, and were fed a total mixed ration consisting of $37 \%$ alfalfa hay, $36 \%$ grain mix, $10 \%$ whole cottonseed, $12 \%$ almond hulls, $2 \%$ soybean meal, and 3\% mineral mix (DM basis) at 0400, 1100, and $1600 \mathrm{~h}$.

\section{Experimental Procedures}

During the experiment, animals were moved to a test area located $20 \mathrm{~m}$ away from the home pen. The testing area contained 3 standing areas (stalls) each $2.4 \mathrm{~m} \times$ $1.2 \mathrm{~m}$ wide and separated by steel panels (Powder River Inc., Provo, UT). Each stall had (1) a smooth poured concrete surface under all legs (0-ROUGH), (2) roughened concrete surface under all legs (4-ROUGH), or (3) the same rough surface under 1 hind quarter (1-ROUGH) while other legs were on smooth concrete (Figure 1). All floors were created by closely aligning 8 square $(30 \times 30 \mathrm{~cm})$ concrete slabs that were $7.6 \mathrm{~cm}$ thick and placed on level ground. Rough surfaces were these same concrete slabs, but with 49 equally distributed 4-sided trapezoidal prism-shaped protrusions from the top of each slab, created with a concrete mold. This rough treatment was chosen to create discomfort, similar to the protruding rocks or screws treatments used by Neveux et al. (2006), but not to cause injury during $1 \mathrm{~h}$ of standing.

In a crossover design, each cow was tested once on each treatment for $1 \mathrm{~h} / \mathrm{d}$, with the order of exposure balanced across the study. The location of the floors in the testing area relative to one another and placement (right or left hind leg) of 1-ROUGH treatment was balanced over the course of the study and switched between every group of cows. Cows were tested in groups of 6 to provide resting time between test days; at least $46 \mathrm{~h}$ of resting time was provided between each treatment. During the $1 \mathrm{~h}$ of testing, 2 horizontal metal bars were placed on the back end of the stall to confine the cows. They were able to move their heads, look sideways, 


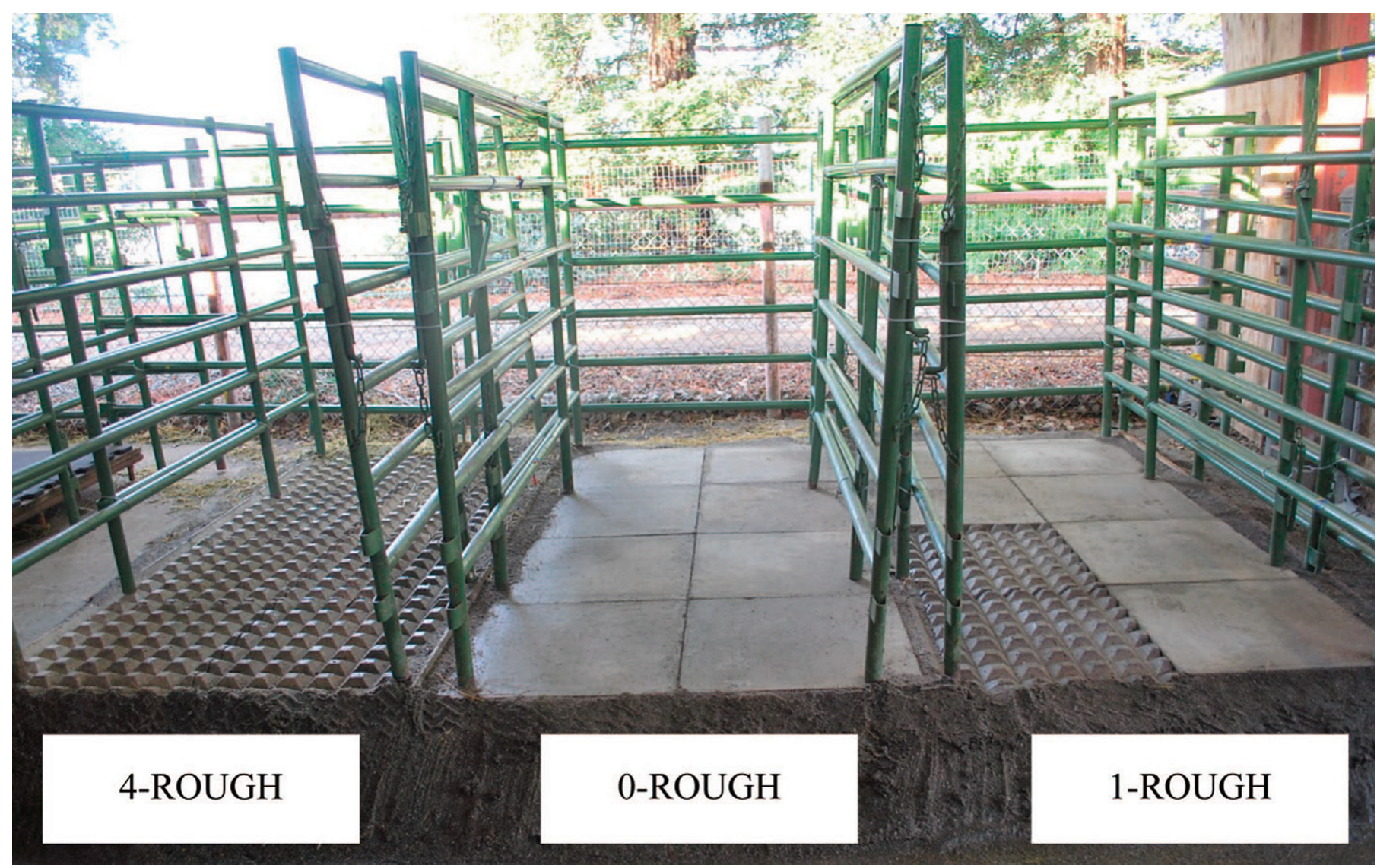

Figure 1. Photograph illustrating the 3 treatment surfaces (1-ROUGH $=$ rough surface under 1 hind leg, smooth concrete under others; 4-ROUGH = rough surface under all legs; 0-ROUGH = smooth concrete surface under all legs). Color version available online.

and take a few steps forward or backward, but each leg remained on the intended treatment.

\section{Behavior Observations}

Stepping Behavior During Treatments. All steps during the 1 -h tests were continuously recorded by trained live observers using data input software Etholog version 2.2 (Ottoni, 2000). The total number of steps per minute and time between each consecutive step were calculated for each surface. Observers had $\geq 92 \%$ intraand inter-observer reliability, measured by correlation with an experienced person (E. Rajapaksha) as a gold standard. A step was defined as lifting any part of the hoof off the ground. Steps were recorded separately for all 4 legs. For 2 cows, video recordings were used in place of live observers because of software malfunction. The video recordings were collected with 4 CVC627B color CCTV video cameras (Speco Technologies, Amityville, NY) connected to a digital video recorder with a GV-1120/1240/1480 combo card (USA Vision Systems Inc., Irvine, CA) and IPD-NVR16 digital surveillance software (ClearVision Inc., Wheeling, IL). The hind leg on the 1-ROUGH surface was identified as the roughtreated leg and the other hind leg as the non-roughtreated hind leg, and the 2 front legs were identified as nonaffected ipsilateral and contralateral front legs. These labels were applied in all treatments to facilitate comparisons with the appropriate leg.

Lying and Standing Behavior. Both lying and standing behavior were recorded with Onset Pendant $\mathrm{G}$ data loggers $(64 \mathrm{~K}$, Onset Computer Corporation, Bourne, MA). The loggers were embedded in a silicone block, wrapped with VetWrap cohesive bandage (3M Products, St. Paul, MN), and placed directly on the medial plane of the leg. Loggers were set to record the $\mathrm{y}$-axis at 30-s intervals, and lying and standing data points were summarized using a SAS code (UBC AWP, 2013). Isolated readings (representing both 30 and 60 s) of lying and standing were deleted following the algorithm and validation described by Ledgerwood et al. (2010). Latency to lie down after testing (after the end of last SEMG measure), the length of the last standing and lying bout before $1 \mathrm{~h}$ testing, and total lying down time during the course of the study were calculated using these data. 


\section{SEMG Evaluations}

Before testing, cows were prepared for SEMG recordings according to the procedure described by Rajapaksha and Tucker (2014). Eight self-adhesive bipolar surface electrodes (3M Red Dot Repositionable Electrodes, $\mathrm{Ag} / \mathrm{AgCl}, 3 \mathrm{M}$, St. Paul, MN) were attached to the skin over both sides of the cow. Two muscles, the middle gluteal (an extensor of the hip joint and abductor of the leg that controls hip movements) and the biceps femoris (extensor of the hip and stifle and flexure of the stifle), were evaluated. Cows were then moved to treatment surfaces and restrained for SEMG recordings. An electromyography telemetric system (Megawin Biomonitor ME 6000, Mega Electronics Ltd., Kuopio, Finland) that was placed above the cow was used to record SEMG readings during both static and dynamic muscle contractions. All SEMG signals recorded at a sample rate of $1,000 \mathrm{~Hz}$ were preamplified (input impedance $=10 \mathrm{G} \Omega$, gain 305) and filtered with a low pass Butterworth filter (bandwidth $8-500 \mathrm{~Hz}$ ). Common mode rejection ratio for the instrument was $110 \mathrm{~dB}$. Data recording and preparation for analysis were done with Megawin version 2.3 (Mega Electronics Ltd.). Recorded raw signals were fast Fourier transformed for frequency domain analysis, and SEMG power spectra were created and used to acquire median power frequency (MPF) values for all muscle contrac- tions. Median amplitude (MA) and total muscle activity during $1 \mathrm{~h}$ were calculated for statistical analysis by using root mean square average of the raw signals.

Static Contractions. Static contractions were measured during standing on treatment surfaces to compare muscle activity change over time and measure fatigue in tested muscles. A total of 5 measures of static contractions were taken at the start $(0 \mathrm{~min})$ and at every 15 min thereafter. To generate static contractions, cows were forced to transfer their weight to each hind leg, in turn, by placing a wooden board with fixed carriage bolts covered by a thin rubber mat under the other hind leg. Readings were recorded for both muscles for $30 \mathrm{~s}$, and then repeated for the other hind leg. Differences of MPF and MA values from static contractions between every 15-min reading and the reading at the start (e.g., $15 \mathrm{~min}-0 \mathrm{~min}$ ) were used to evaluate muscle fatigue (decreased MPF, increased MA; Luttman et al., 2000).

Dynamic Contractions. Continuous SEMG recordings during standing were recorded for each 1-h test session. Six hind leg steps within the first $15 \mathrm{~min}$ and 6 steps in the last 15 min of standing were isolated. The differences between the first and last $15 \mathrm{~min}$ of MPF and MA values were used to evaluate fatigue during dynamic contractions. To evaluate sustained muscle activity, readings were divided into 10 -s segments and categorized based on which leg(s) (left, right, or both) was predominantly active (Figure 2). The number of

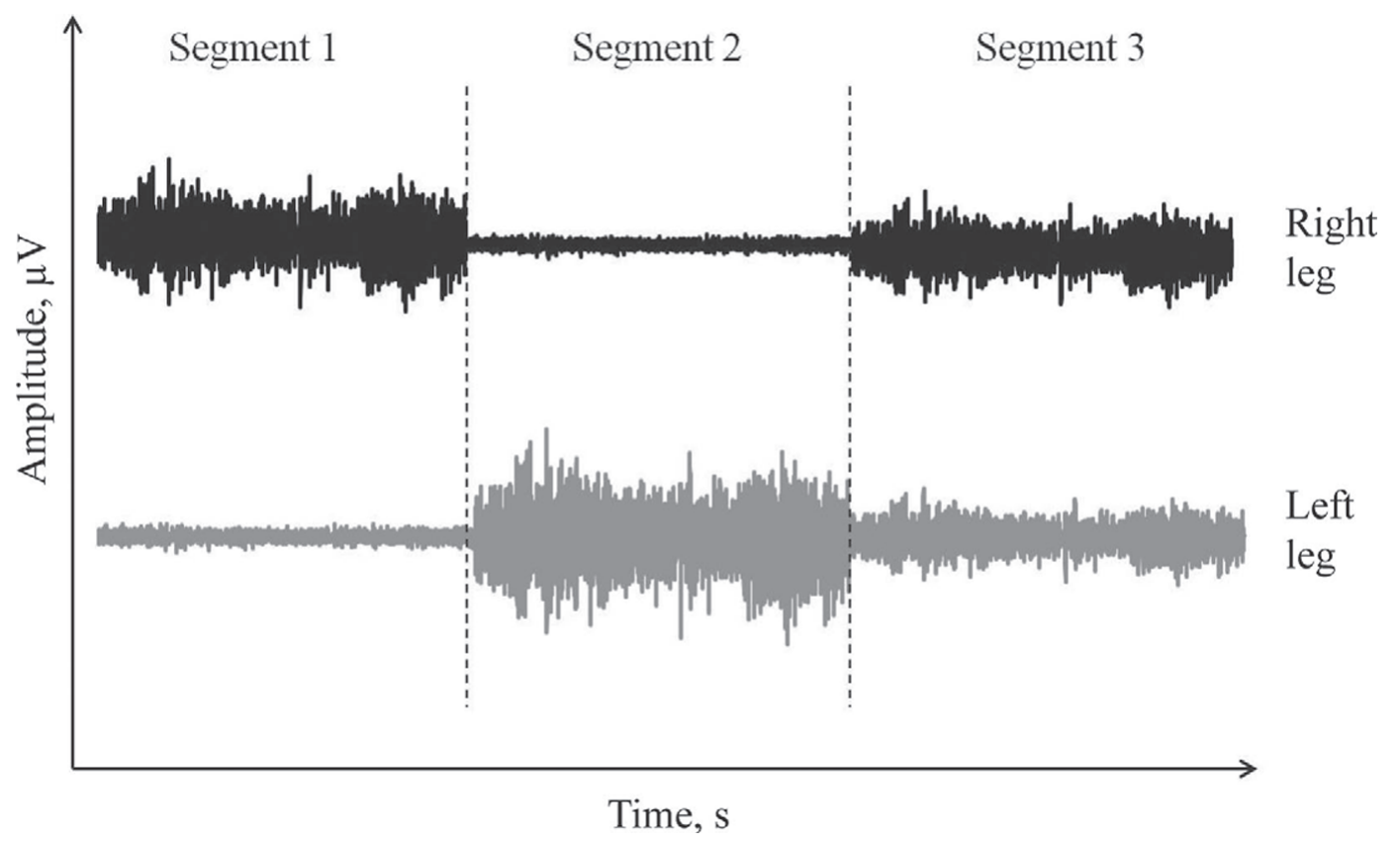

Figure 2. Schematic representation of muscle activity movement between the 2 hind legs for middle gluteal muscle. Segment 1 indicates

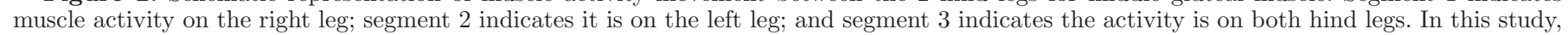

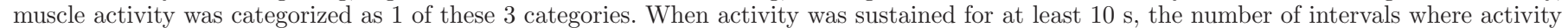

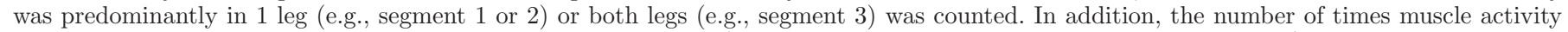
moved from $1 \mathrm{leg}$ to the other or to both legs was also tabulated (referred to as muscle activity movement throughout). 
10-s segments in which the activity was predominantly in the right leg, left leg, or equally in both legs was counted. In addition, the number of times muscle activity moved from $1 \mathrm{leg}$ to the other or to both legs was also tabulated (muscle activity movement; Figure 2). No minimum requirement for the amount of time was associated with these movements. Total muscle activity (associated with all steps and standing activity) generated by both standing and stepping was calculated.

\section{Statistical Analysis}

All statistical analyses were performed using the cow as the experimental unit; cows were tested in groups of 6 and this is reflected in the model used. Steps per minute for all 4 legs in total, each individual leg, variability in time between steps $(\mathrm{CV})$, and latency to lie down were analyzed using a general linear model (PROC GLM, SAS Institute Inc., Cary, NC). Residuals were examined to verify normality and homogeneity of variance. The model included terms for group (cow), day, and floor type. To examine the effect of time within the 1-h test, steps per minute was calculated in to 4 separate 15 -min intervals. These values were then tested using a model that included terms for group (cow), day, time, floor type, and interactions between time and floor type. This model accounted for Greenhouse-Geisser correction. Surface electromyography values, and MPF and MA values from left and right legs were averaged for each muscle for muscle fatigue analysis. Total muscle activity was analyzed for both back legs and individual legs. All muscle activity parameters during $1 \mathrm{~h}$, and total muscle activity change over time (calculated as differences between the start of the experiment and the end of each 15-min interval), were analyzed using the same statistical models described for stepping behavior. For all models, pairwise comparisons of treatment were explored with Tukey's test when the overall $P$-value was significant. Finally, the relationship between steps per minute and total muscle activity was explored by Pearson correlation analysis separately for each treatment (PROC CORR, SAS Institute Inc.).

\section{RESULTS}

\section{Behavioral Observations}

No treatment differences were found in the total number of steps per minute (Table $1, P=0.153, F_{2,44}$ $=2.0$ ) during $1 \mathrm{~h}$ of standing. In 1-ROUGH, steps per minute were greater in the rough-treated leg $(P<$ 0.001, $\left.F_{2,44}=44.1\right)$ and steps per minute were fewer for the other 3 legs $\left(P=0.001, F_{2,44}=8.3\right)$ than in 0 - or 4 -ROUGH. Specifically, fewer nonaffected hind leg $(P$ $\left.<0.001, F_{2,44}=23.7\right)$ and ipsilateral front leg steps $(P$ $\left.=0.001, F_{2,44}=7.5\right)$ were taken on the 1 -ROUGH surface. Stepping patterns were also affected. Variability in time was greater between steps on the 4-ROUGH treatment (Figure 3, as measured by CV, $P<0.001$, $F_{2,44}=24.2$ ). In addition, stepping increased with time on all testing surfaces (Figure 4, all 4 legs: $P=0.001$, $F_{3,132}=7.4$; rough-treated leg: $P=0.001, F_{3,132}=5.6$; all 3 non-rough-treated legs: $P=0.001, F_{3,132}=5.9$ ). An interaction was found between time and treatment for steps per minute on all 3 non-rough-treated legs, with those on 1-ROUGH remaining constant over time, whereas the others increased during the hour of standing (Figure $4, P=0.040 ; F_{6.132}=2.3$ ).

Overall, cows spent $12 \pm 1.9 \mathrm{~h} / \mathrm{d}$ (mean $\pm \mathrm{SD}$ ) lying during the experiment, with no treatment differences in the latency to lie down after testing $(84 \pm 75.2 \mathrm{~min}$; mean $\pm \mathrm{SD} ; P=0.815, F_{2,44}=0.2$ ) or in the length of the first lying bout after testing $(85 \pm 41.5$ min; mean $\left.\pm \mathrm{SD} ; P=0.169, F_{2,44}=1.9\right)$. Similarly, both standing and lying times immediately before cows were tested on the treatment surfaces were not different $(P \geq 0.310$, $F_{2,44} \geq 1.2$ ) among the 3 surfaces.

\section{SEMG Evaluation}

Muscle Activity Location. Muscle activity was located predominantly in the rough-treated leg less often (Table 2, $P<0.001, F_{2,44}=35.6$ ), and in the non-rough-treated leg more often $\left(P<0.001, F_{2,44}=\right.$ 132.1) on the 1-ROUGH surface compared with the other 2 treatments. The number of 10 -s segments where cows predominantly used muscles in both hind legs differed among all treatment surfaces $\left(P \leq 0.026, F_{2,44}=\right.$ 49.9 ) with lowest number on 1-ROUGH and highest on 0 -ROUGH. Total number of muscle activity movements between the hind legs was lower on 1-ROUGH $(P=$ $\left.0.009, F_{2,44}=8.3\right)$ compared with the other treatments. Muscle activity movements did not change with time in any of the treatments $\left(P \geq 0.134, F_{3,132}=1.9\right)$.

Muscle Fatigue and Total Muscle Activity. For both static and dynamic contractions, no significant treatment differences were observed for the differences of MPF or MA between the start and end of testing (static: $P \geq 0.507, F_{2,44} \leq 0.7$; dynamic: $P \geq 0.237$, $\left.F_{2,44} \leq 1.6\right)$. In addition, no significant differences were observed in MPF and MA values measured at the four 15-min intervals of static contractions (Table $3, P \geq$ $\left.0.068, F_{2,44}=3.0\right)$. During $1 \mathrm{~h}$ of standing, total muscle activity per minute from both hind legs combined did not differ among standing surfaces (Table 1, $P=$ $\left.0.219, F_{2,44}=1.6\right)$. Total muscle activity per minute was lower $\left(P=0.004, F_{2.44}=6.1\right)$ in the rough-treated leg and higher $\left(P<0.001, F_{2,44}=20.2\right)$ on the non- 
Table 1. Steps per minute (least squares means, SE) and total muscle activity ( $\mu \mathrm{V}$, least squares means, $\mathrm{SE}$ ) during $1 \mathrm{~h}$ of standing on each treatment surface

\begin{tabular}{|c|c|c|c|c|c|}
\hline \multirow[b]{2}{*}{ Item } & \multicolumn{3}{|c|}{ Treatment $^{1}$} & \multirow[b]{2}{*}{$\mathrm{SE}$} & \multirow[b]{2}{*}{$P$-value } \\
\hline & 1-ROUGH & 4-ROUGH & 0-ROUGH & & \\
\hline \multicolumn{6}{|l|}{ Steps/min } \\
\hline Rough-treated hind leg & $3.1^{\mathrm{a}}$ & $1.5^{\mathrm{b}}$ & $1.4^{\mathrm{b}}$ & 0.14 & $<0.001$ \\
\hline Non-rough-treated hind leg & $0.6^{\mathrm{a}}$ & $1.5^{\mathrm{b}}$ & $1.5^{\mathrm{b}}$ & 0.10 & $<0.001$ \\
\hline Both back legs & $3.7^{\mathrm{a}}$ & $3.0^{\mathrm{b}}$ & $2.9^{\mathrm{b}}$ & 0.19 & 0.009 \\
\hline Contralateral front leg & 1.0 & 0.8 & 0.8 & 0.07 & 0.107 \\
\hline Ipsilateral front leg & $0.5^{\mathrm{a}}$ & $0.8^{\mathrm{b}}$ & $0.8^{\mathrm{b}}$ & 0.06 & 0.002 \\
\hline Both front legs & 1.5 & 1.6 & 1.5 & 0.12 & 0.583 \\
\hline All 3 non-rough-treated legs & $2.1^{\mathrm{a}}$ & $3.1^{\mathrm{b}}$ & $3.1^{\mathrm{b}}$ & 0.19 & 0.001 \\
\hline Total steps (all legs) & 5.1 & 4.6 & 4.5 & 0.28 & 0.153 \\
\hline \multicolumn{6}{|l|}{ Total muscle activity, $\mu \mathrm{V}$} \\
\hline Rough-treated leg & $89.3^{\mathrm{a}}$ & $123.4^{\mathrm{b}}$ & $131.5^{\mathrm{b}}$ & 9.04 & $<0.001$ \\
\hline Non-rough-treated hind leg & $197.0^{\mathrm{a}}$ & $123.8^{\mathrm{b}}$ & $121.3^{\mathrm{b}}$ & 9.42 & $<0.001$ \\
\hline Both back legs & 143.1 & 123.6 & 126.4 & 8.42 & 0.219 \\
\hline
\end{tabular}

${ }^{a-c}$ Different lowercase superscripts indicate significant differences among the 3 treatments.

${ }^{1} 1$-ROUGH $=$ rough surface under 1 hind leg, smooth concrete under others; 4-ROUGH = rough surface under all legs; 0-ROUGH $=$ smooth concrete surface under all legs.

rough-treated leg in 1-ROUGH compared with 4- and 0-ROUGH. Total muscle activity (calculated for both hind legs combined and separately for each hind leg) decreased over time during standing for all treatments (Figure $4, P<0.001, F_{3,132} \geq 7.3$ ), and no interac-

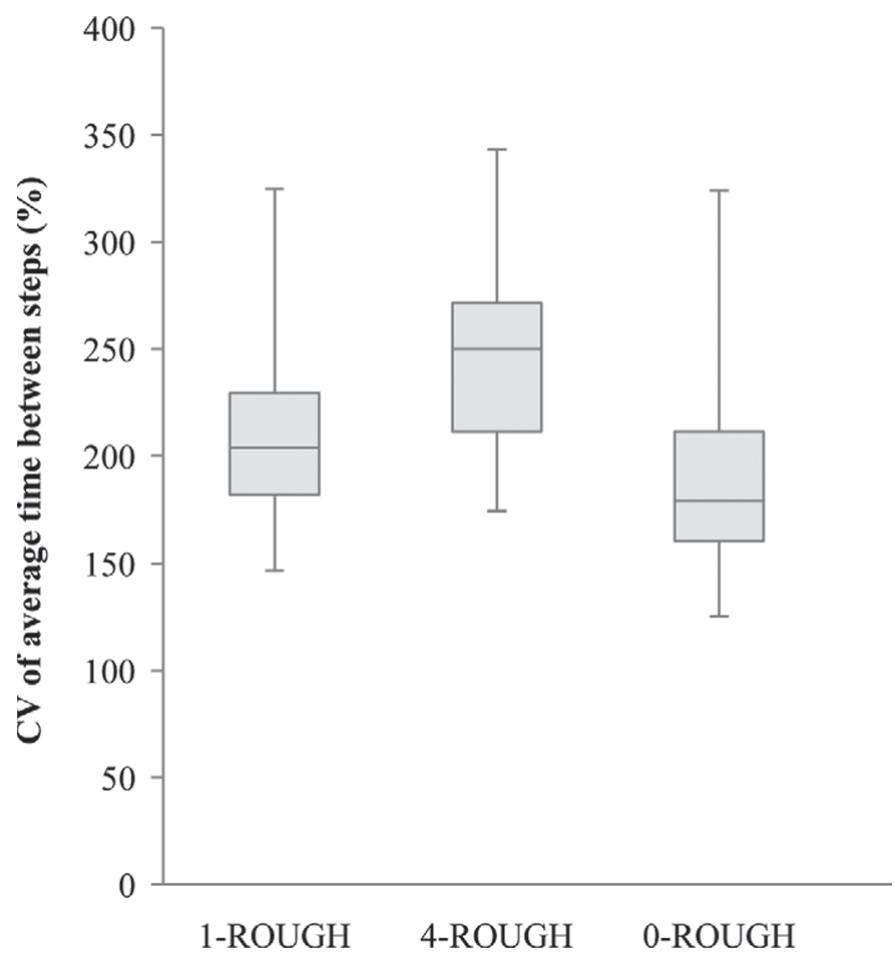

Figure 3. Box plot (median, first and third quartiles) of CV of average time between steps (\%) during $1 \mathrm{~h}$ of standing on each treatment surface $(1-\mathrm{ROUGH}=$ rough surface under 1 hind leg, smooth concrete under others; 4-ROUGH = rough surface under all legs; 0-ROUGH = smooth concrete surface under all legs). tion was found between time and treatment surfaces $\left(P \geq 0.413, F_{6,132} \geq 0.6\right)$. No correlation was observed between steps per minute and total muscle activity per minute in the hind legs (1-ROUGH: $\mathrm{r}=-0.094, P=$ 0.662; 4-ROUGH: $\mathrm{r}=-0.195, P=0.362$; 0-ROUGH: $\mathrm{r}$ $=-0.133, P=0.535)$.

\section{DISCUSSION}

This study assessed dairy cow behavior and muscle activity in response to rough flooring presented under 0 , 1 , or 4 legs. When presented under a single hind leg, cows responded to rough flooring by taking more steps with the rough-treated hind leg and fewer with the other 3 legs on smooth concrete. In contrast, when roughness was presented under all 4 legs, cows increased variability in time between steps compared with the 0 - or 1-ROUGH treatments. Steps per minute increased and muscle activity decreased with time spent on all surfaces, regardless of method of presentation.

When roughness was presented under a single leg, cows took more steps with the hind leg on the rough floor. This response was accompanied by a reduction in the number of steps from both the contralateral non-roughtreated hind leg and the ipsilateral front leg. Muscle activity parameters provided insight into the meaning of these changes in stepping behavior. In the 1-ROUGH treatment, muscle activity on the rough-treated leg was lower than the hind leg on smooth concrete. The higher muscle activity on the non-rough-treated hind leg suggests that cows were shifting their weight toward this leg because weight bearing correlates to activity of muscles in animals (De Leon et al., 1998; Gregor et al., 2006). It was also found that on the 1-ROUGH surface, 
(A) Total, all 4 legs

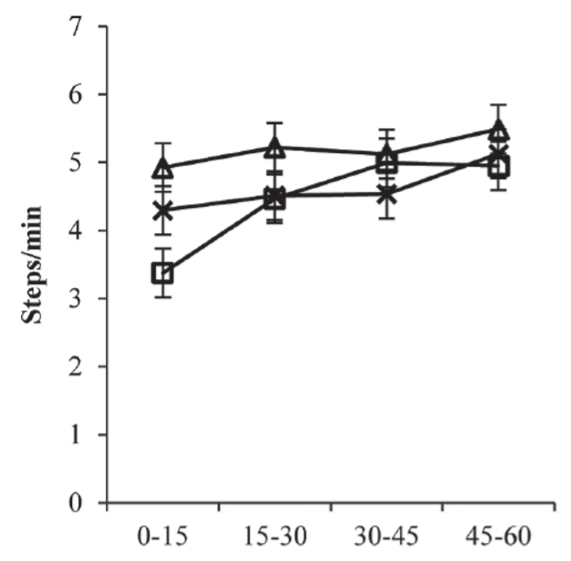

(C) Rough-treated hind leg

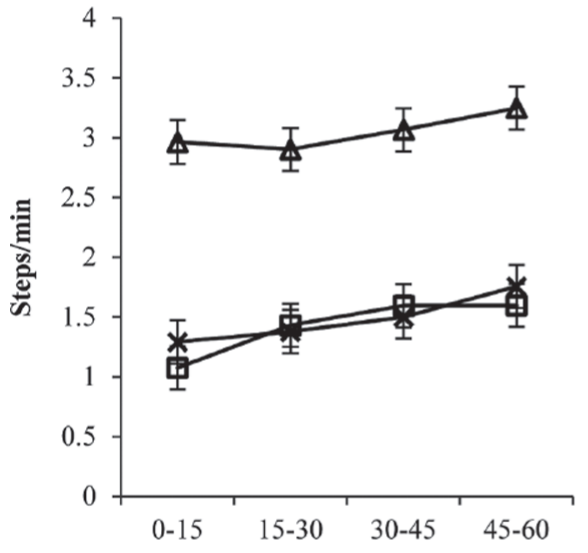

(E) Non-rough-treated 3 legs

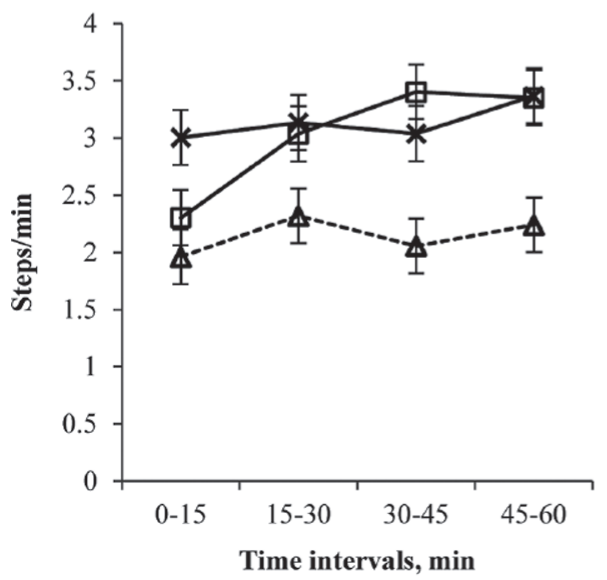

(B) Both hind legs

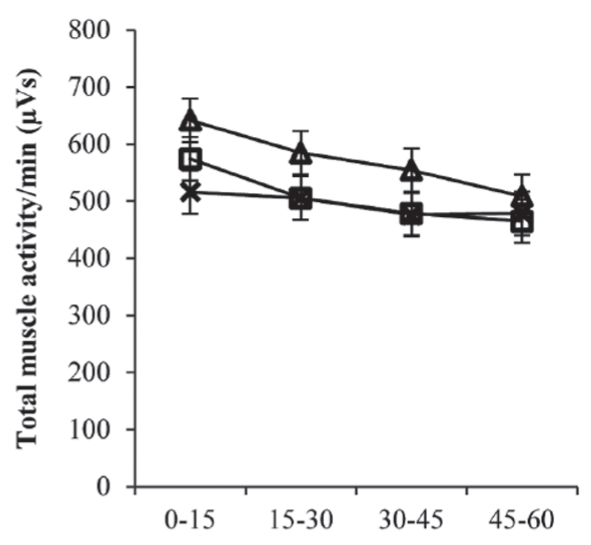

(D) Rough-treated hind leg

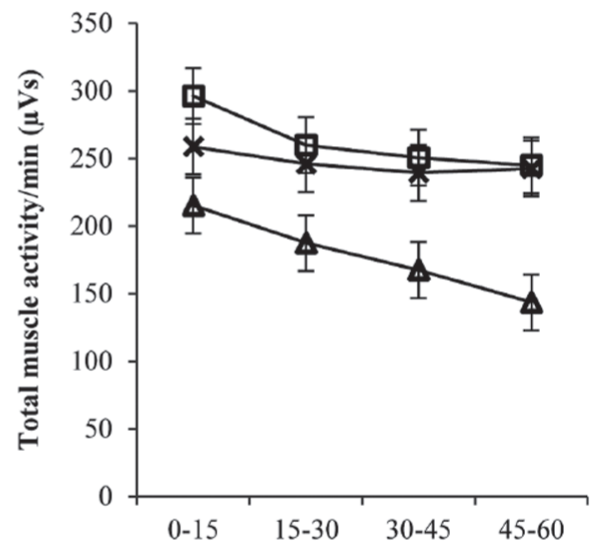

(F) Non-rough-treated hind leg

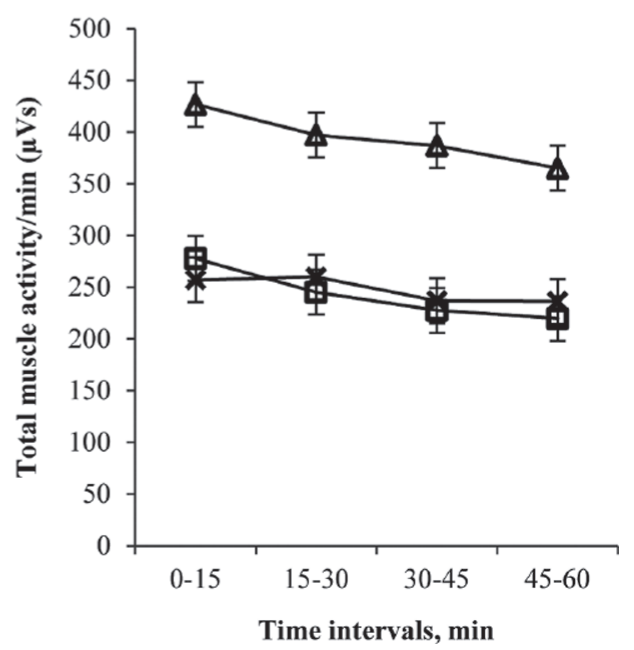

Figure 4. Average steps/min on all 4 legs (panel A), rough-treated hind leg (panel C) and non-rough-treated 3 legs (panel E), and total muscle activity of both hind legs (panel B), rough-treated hind leg (panel D), and non-rough-treated hind leg (panel F) during each of four 15min standing intervals during $1 \mathrm{~h}$. Treatments were 1 -ROUGH $=$ rough surface under 1 hind leg, smooth concrete under others; 4-ROUGH = rough surface under all legs; 0-ROUGH = smooth concrete surface under all legs. Error bars describe least squares means, SE. Rough-treated leg refers to the leg that is placed on the rough surface of the 1-ROUGH and the same leg (left or right, same for a given cow, and balanced across treatments) in the other treatments. 
Table 2. Number of 10-s segments that muscle activity was located in the rough-treated leg, the non-roughtreated leg, and equally between the 2 hind legs (least squares means, SE), and total number of muscle activity movements (Figure 2) between legs during $1 \mathrm{~h}$ of standing on each treatment surface

\begin{tabular}{|c|c|c|c|c|c|}
\hline \multirow[b]{2}{*}{ Item } & \multicolumn{3}{|c|}{ Treatment $^{1}$} & \multirow[b]{2}{*}{$\mathrm{SE}$} & \multirow[b]{2}{*}{$P$-value } \\
\hline & 1-ROUGH & 4-ROUGH & 0-ROUGH & & \\
\hline \multicolumn{6}{|l|}{ Muscle activity location/min } \\
\hline Rough-treated leg & $0.1^{\mathrm{a}}$ & $0.6^{\mathrm{b}}$ & $0.5^{\mathrm{b}}$ & 0.03 & $<0.001$ \\
\hline Non-rough-treated leg & $1.5^{\mathrm{a}}$ & $0.5^{\mathrm{b}}$ & $0.5^{\mathrm{b}}$ & 0.05 & $<0.001$ \\
\hline Both hind legs & $0.5^{\mathrm{a}}$ & $1.0^{\mathrm{b}}$ & $1.3^{\mathrm{c}}$ & 0.05 & $<0.001$ \\
\hline \multicolumn{6}{|l|}{ Muscle activity movements/min } \\
\hline Total movements between hind legs & $0.61^{\mathrm{a}}$ & $0.8^{\mathrm{b}}$ & $0.8^{\mathrm{b}}$ & 0.04 & 0.001 \\
\hline
\end{tabular}

the transfer of muscle activity to the non-rough-treated leg was sustained; fewer muscle activity movements were found between hind legs. These findings are in agreement with previous weight distribution studies in healthy (Neveux et al., 2006) and lame cows (Chapinal et al., 2010) where cows took more steps with the leg exposed to discomfort (either through flooring or lameness) and transferred weight toward the contralateral leg. Together, these results indicate that cows will move legs away from rough floors when possible.

In contrast, when roughness was presented under all 4 legs, stepping rate did not change relative to smooth concrete, likely because cows had no alternative toward which to shift their weight. Instead, in the 4-ROUGH treatment, cows expressed restless behavior differently, with more variability in the time between steps compared with the other 2 methods of presentation. This indicates that when roughness is unavoidable, cows changed the pattern of stepping without changing the total number of steps. Surface electromyography findings also support this argument. On the 0- or 4-ROUGH surface, cows did not sustain muscle activity in a single leg as observed on the 1-ROUGH surface. In addition, on 0- and 4-ROUGH surfaces, the number of 10 -s segments of muscle activity located in the both hind legs was higher than in the 1-ROUGH treatment.

Table 3. Median power frequency (MPF, Hz) and median amplitude (MA; $\mu \mathrm{V}$ ) value differences (least squares means, SE) between start and each 15-min time increment for biceps femoris and middle gluteal muscles measured for all 3 treatments

\begin{tabular}{|c|c|c|c|c|c|c|}
\hline \multirow[b]{2}{*}{ Item } & & \multicolumn{3}{|c|}{ Treatment $^{1}$} & \multirow[b]{2}{*}{$\mathrm{SE}$} & \multirow[b]{2}{*}{$P$-value } \\
\hline & & 1-ROUGH & 4-ROUGH & 0-ROUGH & & \\
\hline \multicolumn{7}{|c|}{ Biceps femoris } \\
\hline & 15 min - start & -0.4 & 0.3 & -1.3 & 0.9 & 0.422 \\
\hline & 30 min - start & -0.3 & -0.3 & -1.5 & 1.2 & 0.744 \\
\hline & 45 min - start & -0.1 & 1.8 & -1.1 & 0.9 & 0.082 \\
\hline & $60 \min -$ start & 0.2 & 1.5 & -1.0 & 1.5 & 0.514 \\
\hline $\mathrm{MA}$ & 15 min - start & -5.0 & -5.0 & -7.0 & 1.6 & 0.556 \\
\hline & 30 min - start & -5.7 & -6.5 & -8.8 & 1.9 & 0.489 \\
\hline & 45 min - start & -5.5 & -5.5 & -11.0 & 2.0 & 0.084 \\
\hline & $60 \min -$ start & -8.9 & -8.3 & -10.2 & 2.0 & 0.786 \\
\hline \multicolumn{7}{|c|}{$\begin{array}{l}\text { Middle gluteal } \\
\text { MPF }\end{array}$} \\
\hline & 15 min - start & -0.4 & -0.9 & -1.0 & 1.4 & 0.951 \\
\hline & 30 min - start & -1.0 & -0.1 & 1.1 & 1.6 & 0.652 \\
\hline & $45 \min -$ start & -1.0 & -0.8 & 3.6 & 1.5 & 0.062 \\
\hline \multirow{2}{*}{\multicolumn{7}{|c|}{ ov ImIn- stale }} \\
\hline & & & & & & \\
\hline & 30 min - start & -9.1 & $\begin{array}{l}-0.1 \\
-5.7\end{array}$ & $\begin{array}{l}-4.1 \\
-3.5\end{array}$ & $\begin{array}{l}0.0 \\
3.6\end{array}$ & $\begin{array}{l}0.002 \\
0.549\end{array}$ \\
\hline & 45 min - start & -10.2 & -7.5 & -0.6 & 3.2 & 0.110 \\
\hline & $60 \min -$ start & -7.5 & -8.9 & -4.6 & 4.1 & 0.749 \\
\hline
\end{tabular}

${ }^{1} 1$-ROUGH $=$ rough surface under 1 hind leg, smooth concrete under others; 4-ROUGH = rough surface under all legs; 0-ROUGH = smooth concrete surface under all legs. 
This indicates altered muscle use may be a mechanism of how dairy cows respond to standing surfaces under all 4 legs, which is distinct from when it is only under a single leg. It also explains, perhaps, why previous studies have not been able to detect differences among surfaces presented under all 4 legs using steps per minute or weight distribution as dependent variables (e.g., Krebs et al., 2011; Chapinal and Tucker, 2012).

Indeed, it seems that muscle activity provides unique information about cattle responses. No correlation is present between the frequency of steps and total combined muscle activity of the 2 hind legs in this work or in Rajapaksha and Tucker (2014). Of the 2, muscle activity is a broader response in that it plays a role both in upright stature as well as any movement. In addition, we documented that muscle activity movements occurred between legs without any lifting the hoof off the ground (stepping). Chapinal and Tucker (2012) also reported that weight distribution changes were not correlated with steps. The lack of relationship between these 2 measures is illustrated in the response to rough flooring under a single hind leg. The 1-ROUGH surface resulted in lower total muscle activity on the roughtreated leg, although this leg had a higher number of steps per minute. Thus, it is important to understand stepping behavior in combination with muscle activity (or weight bearing) to interpret the animal's response.

Across studies, including the current work, stepping rate increases with time spent standing (Cooper et al., 2007; Chapinal et al., 2011; Krebs et al., 2011; Rajapaksha and Tucker, 2014). Previously, this change has been interpreted as discomfort; however, we still lack evidence that negative affective states are associated with this change. Functionally, cattle may engage in more movement the longer they stand to increase blood circulation and reduce venous pooling of blood in the muscles, because both of these mechanisms are used to reduce muscle fatigue and discomfort in humans (Freitas et al., 2005). Additional work is needed to interpret this response in terms of animal welfare.

Regardless of treatment, cattle did not experience fatigue, as measured by decreased MPF and increased MA, over the $1 \mathrm{~h}$ of standing. Similarly, when SEMG were used to evaluate the effect of floor slope, no indication of fatigue was found when comparing MPF and MA values at the start and end of 90 min of standing (Rajapaksha and Tucker, 2014). Several explanations are possible for these results. First, it is possible that the static contractions used to evaluate fatigue do not generate enough reference volumetric contraction to detect fatigue in cows. Alternatively, the 1-h standing time may not cause muscle fatigue because cattle regularly stand for longer periods of time (Ito et al., 2009). However, the greatest magnitude of muscle activity de- crease was observed in the hind leg on smooth concrete in 1-ROUGH (61.5 vs. $20.9 \mu \mathrm{V}$, in 1-ROUGH vs. the other 2 treatments). This leg had most sustained muscle contraction and, therefore, would be the best candidate for fatigue if cows were tested for longer periods.

Finally, the method used to present flooring surfaces, with rough material under 0,1 , or 4 legs, altered both muscle activity and stepping behavior. These results have implications for how comfort while standing is studied in the future. For example, it is particularly important to monitor time between steps when surfaces are presented under all 4 legs, a variable that has not been included in previous work. In addition, these findings also raise questions about how to study other forms of discomfort, such as lameness. Cows may be subjected to pain in either both hind legs and both limbs on a single side (e.g., lameness occurs in more than 1 limb; Whay et al., 1998). Neveux et al. (2006) found that when pain is under both hind limbs, cows could not shift weight to the front legs. The studies to date suggest that cattle responses to pain or rough surfaces while standing are stimulus-specific and that it is beneficial to incorporate consideration of this into the dependent variables measured.

\section{CONCLUSIONS}

Stepping behavior and SEMG changed in specific legs when roughness was under 1 hind leg. In contrast, timing between consecutive steps between all legs was more variable when rough flooring was under all 4 legs. Future work should consider both the stimulus-specific nature of these responses while standing and incorporate measures of muscle function or weight distribution, because this and other work demonstrate that SEMG and load cells can detect responses in the absence of observable steps.

\section{ACKNOWLEDGMENTS}

This research was supported by W. K. Kellogg Endowment, Lyons fellowship (funding for Eranda Rajapaksha), and USDA National Institute of Food and Agriculture Multistate Research Project NC1029. We gratefully acknowledge the infrastructure support of the Department of Animal Science, College of Agricultural and Environmental Sciences, and the California Agricultural Experiment Station of the University of California-Davis. We thank University of California-Davis dairy farm manager Doug Gisi, Joseph Banuelos, and the undergraduate interns for their help throughout the experiments. We are also grateful to the University of California-Davis Veterinary orthopedic laboratory for sharing their equipment and software. 


\section{REFERENCES}

Chapinal, N., A. M. de Passillé, J. Rushen, and C. B. Tucker. 2011. Measures of weight distribution and frequency of steps as indicators of restless behavior. J. Dairy Sci. 94:800-803.

Chapinal, N., A. M. de Passillé, J. Rushen, and S. Wagner. 2010. Automated methods for the detection of lameness and analgesia in dairy cattle. J. Dairy Sci. 93:2007-2013.

Chapinal, N., and C. B. Tucker. 2012. Validation of an automated method to count steps while cows stand on a weighing platform and its application as a measure to detect lameness. J. Dairy Sci. 95:6523-6528.

Cook, N. B. 2003. Prevalence of lameness among dairy cattle in Wisconsin as a function of housing type and stall surface. J. Am. Vet. Med. Assoc. 223:1324-1328.

Cooper, M. D., D. R. Arney, and C. J. Phillips. 2007. Two- or fourhour lying deprivation on the behavior of lactating dairy cows. J. Dairy Sci. 90:1149-1158.

De Leon, R. D., J. A. Hodgson, R. R. Roy, and V. R. Edgerton. 1998. Full weight-bearing hind limb standing following stand training in the adult spinal cat. J. Neurophysiol. 80:83-91.

Flower, F. C., and D. M. Weary. 2006. Effect of hoof pathologies on subjective assessments of dairy cow gait. J. Dairy Sci. 89:139-146.

Freitas, S. M. S. F., S. A. Wieczorek, P. H. Marchetti, and M. Duarte. 2005. Age-related changes in human postural control of prolonged standing. Gait Posture 22:322-330.

Gregor, R. J., D. W. Smith, and B. I. Prilutsky. 2006. Mechanics of slope walking in the cat: Quantification of muscle load, length change, and ankle extensor EMG patterns. J. Neurophysiol. 95:1397-1409.

Haufe, H. C., L. Gygax, B. Steiner, K. Friedli, M. Stauffacher, and B. Wechsler. 2009. Influence of floor type in the walking area of cubicle housing systems on the behaviour of dairy cows. Appl. Anim. Behav. Sci. 116:21-27.

Ito, K., D. M. Weary, and M. A. G. von Keyserlingk. 2009. Lying behavior: Assessing within and between herd variation in freestall housed dairy cows. J. Dairy Sci. 92:4412-4420.

Kim, J. Y., C. Stuart-Buttle, and W. S. Marras. 1994. The effects of mats on back and leg fatigue. Appl. Ergon. 25:29-34.

Krebs, N., S. L. Berry, and C. B. Tucker. 2011. Restless behavior increases over time, but not with compressibility of the flooring surface, during forced standing at the feed bunk. J. Dairy Sci. 94:97-105.

Ledgerwood, D. N., C. Winckler, and C. B. Tucker. 2010. Evaluation of data loggers, sampling intervals, and editing techniques for measuring lying behavior of dairy cattle. J. Dairy Sci. 93:5129-5139.

Luttman, L., J. Mattias, and L. Wolfgang. 2000. Electromyographical indication of muscular fatigue in occupational field studies. Int. J. Ind. Ergon. 25:645-660.

Neveux, S., D. M. Weary, J. Rushen, M. A. G. von Keyserlingk, and A. M. de Passillé. 2006. Hoof discomfort changes how dairy cattle distribute their body weight. J. Dairy Sci. 89:2503-2509.
Ottoni, E. B. 2000. EthoLog 2.2-A tool for the transcription and timing of behavior observation sessions. Behav. Res. Methods Instrum. Comput. 32:446-449.

Ouweltjes, W., M. Holzhauer, P. P. J. van der Tol, and J. van der Werf. 2009. Effects of two trimming methods of dairy cattle on concrete or rubber-covered slatted floors. J. Dairy Sci. 92:960-971.

Pastell, M. E., and M. Kujala. 2007. A probabilistic neural network model for lameness detection. J. Dairy Sci. 90:2283-2292.

Platz, S., F. Ahrens, J. Bendel, H. H. D. Meyer, and M. H. Erhard 2008. What happens with cow behavior when replacing concrete slatted floor by rubber coating: A case study. J. Dairy Sci. 91:999-1004.

Rajapaksha, E., and C. B. Tucker. 2014. How do cattle respond to sloped floors? An investigation using behavior and electromyograms. J. Dairy Sci. 97:2808-2815.

Rushen, J., E. Pombourcq, and A. M. de Passillé. 2007. Validation of two measures of lameness in dairy cows. Appl. Anim. Behav. Sci 106:173-177.

Somers, J. G. C. J., K. Frankena, E. N. Noordhuizen-Stassen, and J. H. M. Metz. 2003. Prevalence of claw disorders in Dutch dairy cows exposed to several floor systems. J. Dairy Sci. 86:2082-2093.

Telezhenko, E., L. Lidfors, and C. Bergsten. 2007. Dairy cow preferences for soft or hard flooring when standing or walking. J. Dairy Sci. 90:3716-3724.

Ternman, E., L. Hänninen, M. Pastell, S. Agenäs, and P. P. Nielsen. 2012. Sleep in dairy cows recorded with a non-invasive EEG technique. Appl. Anim. Behav. Sci. 140:25-32.

Tucker, C. B., D. M. Weary, A. M. de Passillé, B. Campbell, and J. Rushen. 2006. Flooring in front of the feed bunk affects feeding behavior and use of freestalls by dairy cows. J. Dairy Sci. 89:2065-2071.

UBC AWP. 2013. UBC Animal Welfare Program: SOP HOBO Data Loggers. Pages 1-23. University of British Columbia, Vancouver, Canada.

USDA. 2009. Dairy 2007, Part V: Changes in dairy cattle health and management practices in the United States 1996-2007. \#519.0709. USDA:APHIS:VS, CEAH. Fort Collins, CO.

Vanegas, J., M. Overton, S. L. Berry, and W. M. Sischo. 2006. Effect of rubber flooring on claw health in lactating dairy cows housed in free-stall barns. J. Dairy Sci. 89:4251-4258.

Vokey, F. J., C. L. Guard, H. N. Erb, and D. M. Galton. 2001. Effects of alley and stall surfaces on indices of claw and leg health in dairy cattle housed in a free-stall barn. J. Dairy Sci. 84:2686-2699.

Whay, H. R., A. E. Waterman, A. J. F. Webster, and J. K. O'Brien. 1998. The influence of lesion type on the duration of hyperalgesia associated with hind limb lameness in dairy cattle. Vet. J. $156: 23-29$ 